\title{
SALAMANCA Y HELENISMO. INTELECTUALES GRIEGOS QUE PASARON \\ POR LA CIUDAD DE SALAMANCA A LO LARGO DE LOS SIGLOS
}

\author{
Styliani Voutsa \\ Profesora de Lengua y Literatura Griega en la Educación Secundaria de Grecia (Rodas)

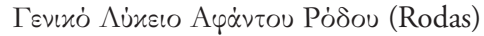 \\ Doctora en Literatura por la Universidad de Salamanca \\ svoutsa@yahoo.com
}

In memoriam ( $\varepsilon i \varsigma \mu v \eta ́ \mu \eta v)$ de Kostas Tsirópoulos, el gran maestro e intelectual griego

\section{RESUMEN}

La ciudad de Salamanca y su histórica Universidad con la tradición en estudios clásicos ha atraído siempre la presencia de profesores e intelectuales griegos y chipriotas. El estudio se centra en cuatro hombres de letras que estuvieron en Salamanca a lo largo de los siglos como profesores universitarios o como admiradores de su Universidad y de sus figuras máximas: Diógenes Paramonaris, Neófitos Rodinós, Kostas Tsirópoulos y Nikos Kazantzakis. La conclusión a la que se llega es que desde el siglo XVI hasta el siglo XX no se ha perdido el vínculo entre Salamanca y Helenismo, sino que ha estado presente de varias maneras.

Palabras ClaVE: Salamanca, Helenismo, Universidad, griego clásico.

\author{
SALAMANCA AND HELLENISM. \\ GREEK INTELLECTUALS WHO HAVE VISITED THE CITY OF SALAMANCA \\ OVER THE CENTURIES
}

\section{ABSTRACT}

The city of Salamanca and its historical University with tradition in classical studies has always attracted the presence of Greek and Cypriot teachers and intellectuals. This study focuses on four of them who have been in Salamanca over the centuries as academic teachers or as admirers of the famous University and its great figures: Diogenes Paraponaris, Neofitos Rodinos, Nikos Kazantzakis and Kostas Tsiropoulos. The reached conclusion that from $16^{\text {th }}$ century until $20^{\text {th }}$ century the bond between Salamanca and Hellenism has been very strong and present in various ways.

KeYwords: Salamanca, Hellenism, University, Classical Greek.

La relación de la ciudad de Salamanca con Grecia, y, en general, con el helenismo, es un tema que daría pie a una investigación muy interesante y extensa, mucho 
más exhaustiva que las pocas páginas que le dedicaremos aquí en nuestro estudio. La Biblioteca de la Universidad de Salamanca fue, por ejemplo, la sede de numerosos manuscritos griegos antiguos que rescató el eminente filólogo clásico Antonio Tovar. Por otra parte, una especial mención merecerían también las relaciones que se establecieron entre griegos y españoles en la época en que Grecia estuvo bajo la ocupación del imperio otomano (la llamada en griego Turcocracia / Tоэркократі́). Sin embargo, en este artículo nos vamos a centrar sólo en el caso de cuatro intelectuales griegos que de alguna manera se relacionaron con la polis de Salamanca, dos que enseñaron en su Universidad y otros dos que la visitaron y la describen con entusiasmo en sus libros de viajes.

Sobre los griegos que enseñaron en la Universidad de Salamanca nuestra fuente principal de información es la célebre Bibliographie Hellénique, ou Description raisonnée des ouvrages publies par des Grecs au dix-septième siècle, escrita por Émile Legrand (París, 1903, tomo v). Legrand habla de dos eruditos, de DiÓGENES PARAMONARIS


procedentes del Colegio Griego de Roma. El primero, Paramonaris, era oriundo del sur de Grecia, de Peloponeso. En concreto, nació en 1580 en Leontari de Arcadia; de hecho, en algunos documentos lo encontramos nombrado como «Diogenes Paramonarius Lacedaemonius». Su familia está relacionada con la lucha griega de la independencia contra la ocupación otomana (era sobrino de Ioannis Polychrones, uno de los jefes de los revolucionarios en Peloponeso). Según la información que nos proporciona Legrand, citando los archivos del Colegio Griego, Paramonaris entró en el Colegio Griego de Roma en Octubre de 1596, a la edad de dieciséis años, para estudiar la gramática. En consonancia con la Chronique du Collège grec (f. 33 vo), Paramonaris se quedó en el Colegio doce años y tras haber estudiado Filosofía y Teología, recibió el grado del Doctorado y luego se marchó para España:

Diogene Paramonari dalla Morea ${ }^{1}$ fu d' indole buona. Doppo haver studiato la filosofia et teologia, ricevette il grado del dottorato, poi partì dal Collegio, essendo andato in Spagna per suoi bisogni. È stato in Collegio dodeci anni (Legrand, 1903: 234)².

En España, encontramos a Diógenes Paramonaris en Toledo, donde se vincula con el pintor cretense Doménico Theotocópoulos. Con el nombre de «doctor Diogenis Parramonlio» firma el 31 de marzo de 1614 como testigo la autorización que da el moribundo pintor griego a Jorge Manuel para redactar su testamento (Hassiotis, 2014: 52-53).

Paramonaris se instala en la ciudad de Salamanca y enseña la lengua griega en su Universidad (1617-1618): «Diogène Paramonaris était devenu professeur de langue

\footnotetext{
${ }^{1}$ Morea es otra denominación para la región de Peloponeso.

${ }^{2}$ Legrand corrige la información citada de la Chronique afirmando que Paramonaris en realidad estuvo en el Colegio trece años.
} 
grecque à l' université de Salamanques, señala E. Legrand. En concreto, según el profesor José María Floristán, Paramonaris en septiembre de 1617 fue nombrado Catedrático de griego en medias en Salamanca y tomó posesión de su plaza el 19 de octubre. En agosto de 1618 pidió licencia para trasladarse a Madrid para resolver unos negocios y le fue concedida. Desde entonces no regresó a Salamanca (Floristán, 2007: 241-243).

El nombre de Paramonaris en relación con la ciudad de Salamanca lo encontramos también en otro lugar de la Bibliographie Hellenique. En el apartado dedicado al año 1620, Legrand cita un epigrama suyo que alude al libro Reduction de las letras, y arte para enseñar a ablar los mudos, escrito por Juan Pablo Bonet (Legrand, 1903: 39). El epigrama va precedido de las siguientes palabras (que son las que nos

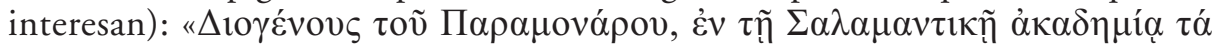

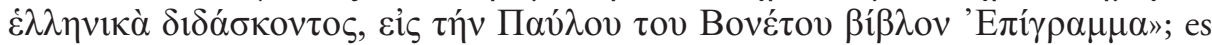
decir, epigrama escrito por Diógenes Paramonaris, profesor de lengua griega en la Academia Salmantina, sobre el libro de Pablo Boneto. Según el catedrático de Historia de la Universidad Aristóteles de Tesalónica, Ioannis Hassiotis, junto al epigrama de Paramonaris se pueden encontrar otros tres textos muy interesantes: uno, en español, del poeta Félix López de Zárate, inspirado en el epigrama de Paraponaris; otro, en griego y latín, del profesor de Esmirna que enseñaba en Alcalá de Henares, Constantino Sofías y, el último, en español, del ya reconocido dramaturgo Félix López de Vega (Hassiotis, 2014: 52-53).

El otro erudito griego es el Chipriota NEÓfITOS RODINÓs, sobre el cual proporciona mucha información el historiador griego y ex profesor del Departamento de Filología Italiana de la Universidad Aristóteles de Tesalónica, Zacarías Tsirpanlís.

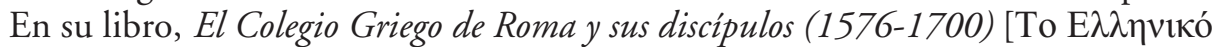

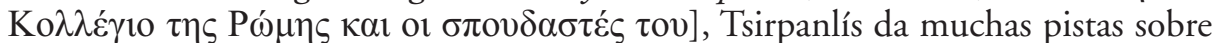
la biografía y la obra de Rodinós. Basado, por una parte, en la ya citada Bibliographie Hellénique de Émile Legrand y, por otra parte, en el estudio de Aristide Brunello titulado "Neofito Rodino, missionario e scrittore ecclesiastico greco del secolo XVII ${ }^{\circ}$, el profesor tesalonicense da los siguientes datos biográficos: Neófitos Rodinós, nacido en el pueblo Potamiós o Potamiú de Chipre, se hizo monje antes de irse a Italia y recibió clases de los maestros Leóncios Eustratios, Iásonas Sozomenós y Máximos Margounios. A Margounio lo acompañó a Roma donde el último fue profesor de la famosa Escuela Griega de Venecia (entre los discípulos de Margounios figuraba Kyrilos Loukaris, el futuro Patriarca de Constantinopla). Rodinós socorrió a su maestro hasta su muerte (1602).

En Venecia parece muy probable que Rodinós se convirtiera al catolicismo la primavera de 1607. Según Adrián Fortescue que cita Ines Angeli Murzaku, la conversión de Rodinós se explica por el hecho de que Margounios, su maestro, fue

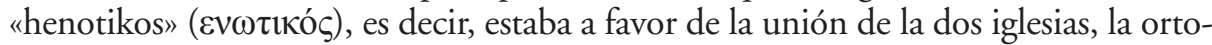
doxa y la católica. Así posiblemente influyó en que se convirtiera el joven Rodinós (Murzaku, 2009: 72). En el Colegio de Roma Rodinós estudió desde 1607 hasta 1610 y cursó las materias de Griego Clásico, Latín y Lógica. Rodinós continuó sus estudios filosóficos y teológicos en la Universidad de Salamanca, donde permaneció seis años, desde 1610 hasta 1616 y enseñó -igual que Paramonaris- el griego clásico 
(1611-1615). Gil Fernández señala que tanto Rodinós como Aramonaris (Paramonaris) en Salamanca y Sofías en Alcalá no dejaron sino «una ligera huella» de su paso por «nuestras Universidades» (Gil Fernández, 2010: 40).

Después de Salamanca lo encontramos en Polonia (donde se ordenó sacerdote), en varios sitios del Medio Oriente (entre el 1620-1622), y hasta 1625 fue profesor en el Mezzojuso de Sicilia. En realidad, Rodinós, culto y activo viajero, nunca pierde sus lazos con Italia: vuelve a Roma en 1629 y entre allí y la ciudad de Barile (zona de Puglia) se queda hasta 1633. Visita Napoli varias veces (1630, $1643,1645,1655)$ y en su Universidad enseña la lengua griega, siendo al mismo tiempo el párroco de la iglesia griega ortodoxa napolitana. Su vida azarosa sigue así, entre viajes, tarea misionera y enseñanzas hasta su muerte (1659).

Demos ahora un salto desde el siglo XVII al siglo XX. Un gran pensador español y un gran pensador griego tienen una charla en la ciudad de Salamanca, en plena Guerra Civil (1936): se trata del vasco Miguel de Unamuno, catedrático de Lengua y Literatura Griega en la Universidad de Salamanca, autor, ensayista, filósofo, poeta

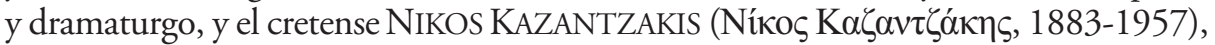
novelista, ensayista, filósofo e intelectual griego de primera fila. Se trata de dos figuras máximas no sólo de sus países respectivos sino de las letras universales que se encontraron en Salamanca y conversaron sobre la situación política de aquel momento de España y del deber del intelectual frente a ella. La entrevista que Unamuno concede a Kazantzakis está comprendida en el libro de este último Viajando. España ( $T \alpha \xi 1-$ $\delta \varepsilon v ́ o v \tau \alpha \varsigma$. I $\sigma \pi \alpha v i ́ \alpha)$, donde el autor griego da constancia de su visita -como corresponsal de periódicos griegos- a varias ciudades españolas, entre ellas Salamanca.

En el prólogo de su libro Kazantzakis afirma con contundencia: «El viaje y la confesión (la creación no es sino la forma más elevada y más exacta de confesión) han sido en esta vida mis dos mayores alegrías» (Kazantzakis, 2002: 7). El autor griego le dedica dos textos de su libro a Salamanca: el primero es un texto escrito en una prosa lírica sobre la emoción que le provoca el paseo por la antigua Universidad, cuya historia el autor griego recrea vivamente con su imaginación ${ }^{3}$ :

Desierto está el gran patio adoquinado de la Universidad. Desde hace tres siglos se apiñaban aquí, gritando, conversando, miles de estudiantes de todas las partes del mundo. ¡Qué vida, qué movimiento y agitación tenía entonces ese nido de la sabiduría! Estudiantes borrachos y libertinos, o pálidos y místicos, iban y venían con sus trajes variopintos - unos de las órdenes de Santiago con la cruz roja como empuñadura de la espada en el pecho, otros con capas verdes, azules o amarillas, otros con hábitos negros o totalmente blancos, pisaban los adoquines del patio grande, se asomaban a las ventanas y conversaban acerca de los silogismos de Aristóteles, la teología de Scott y de Tomás de Aquino o acerca del centro inmóvil del universo,

${ }^{3}$ Ese dato cobra más importancia si pensamos que en aquella época en Grecia se conocían muy pocas cosas de las letras hispanas. 
la Tierra. Aquellos estudiantes estaban organizados de manera democrática, elegían ellos mismos sus profesores, todo el día conversaban y seguían clases de filosofía y teología, y de noche se dedicaban al vino, al canto, a las mujeres o a la oración.

Hoy silencio, soledad, buen tiempo. Sol de invierno, las hierbas abrazan con dulzura y luchan por desplazar los adoquines, un gato blanco está sentado en el umbral y toma el sol (Kazantzakis, 2002: 41).

Kazantzakis hace una especial mención al «simpático y dulcísimo» Fray Luis de León, cuya estatua imponente en el Patio de Escuelas le despierta varios sentimientos y reflexiones. (Detrás de ella se sitúa hoy el Colegio Universitario Fray Luis de León). Para el autor cretense, la figura humilde del Fray Luis constituye un símbolo de la lucha del intelectual y, por extensión, de todo hombre por la verdad y la libertad:

En un rincón del patio se ilumina suavemente por el sol triste la estatua del fraile simpático y dulcísimo Luis de León, del gran poeta lírico y profesor sabio de teología del siglo dieciséis. Seguidor fanático de la lengua popular, predicaba «a toda la espaciosa y triste España» que si queremos que el pueblo se ilustre y se salve debemos escribir en su lengua. Solamente a través de la lengua del pueblo seremos capaces de reavivar a la vez la antigua sabiduría. «Sabios e ignorantes, predicaba el fraile ilustrado, saldrán así todos ganando»" .

Como era de esperar, lo encarcelaron. Cinco años aguantó en la cárcel torturas sin quejarse. Le consolaba la idea de que él también, igual que los primeros cristianos, fue perseguido por la verdad. Además, con el carisma que tenía de dar ritmo a su pesar y convertirlo en verso, aliviaba sus penas. El arte hizo de nuevo su milagro. Abría el poeta encarcelado las puertas cerradas con su verso, cantaba libre, con ternura y melancolía al cielo y a la tierra. Gracia y dulzura inefable, orgullo humilde y noble$\mathrm{za}$, conmoción serena en el cielo lírico. «Aquí la envidia y mentira / me tuvieron encerrado: / dichoso el humilde estado / del sabio que se retira / de aqueste mundo malvado; / y con pobre mesa y casa / en el campo deleitoso, / con sólo Dios se compasa / y a solas su vida pasa, / ni envidiado ni envidioso.»

Cinco años después, lo sacaron de la cárcel. Tranquilamente emprendió el camino para esta Universidad de Salamanca, subió de nuevo a la tarima y empezó otra vez sus clases con la sencilla, habitual frase suya, como si hubiera interrumpido su clase ayer: "Decíamos ayer....» (Kazantzakis, 2002: 41-43).

Kazantzakis termina con una reflexión sobre el papel que ha desempeñado la cadena montañosa de los Pirineos para la historia cultural de España:

${ }^{4}$ El empeño de Fray Luis por que el pueblo aprenda su lengua, la lengua popular y escriba en ella para salvarse de la ignorancia y salir ganando, nos recuerda lo que predicaba con fervor el poeta

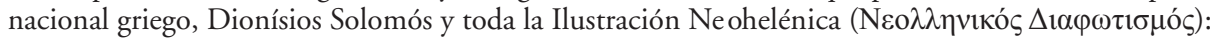
sólo a través de la lengua popular y de la educación el pueblo griego podrá conocer su historia y sentirse fuerte para reivincidar su libertad contra el Imperio Otomano. 
Todo el día vagaba por los callejones de esta maestra degradada -Salamancay los viejos interrogantes venenosos zumbaban a mi alrededor como avispas. Como si el aire estuviera embrujado, como si no se hubieran podrido del todo debajo de las hierbas los apasionados y parlanchines don Quijotes de la sabiduría. Repasaba en mis adentros y veía con qué vehemencia caminó el espíritu sobre las tierras y las piedras de España. Sentí por primera vez que los Pirineos separan Europa de África. El Renacimiento -la unión de la antigua alma griega con la cristiana- que generó nuevas fuentes de alegría y creatividad en las entrañas humanas, no superó los Pirineos. La España ardiente de los romances y del arco gótico y de las melodías arabescas permaneció virgen (Kazantzakis, 2002: 41-43) .

El otro texto que Kazantzakis titula «Salamanca» es el que contiene la famosa entrevista que hace "al terrible puercoespín de Unamuno». La conversación de esos dos intelectuales polifacéticos e inquietos, marcados por las mismas angustias existenciales y dudas metafísicas, es fascinante. Kazantzakis, según sus afirmaciones, ve a un Unamuno envejecido (comparado con el anterior encuentro que tuvieron en Madrid), pero con la misma chispa divina en los ojos. La conversación de los dos hombres gira en torno a la actualidad candente de España, se carga con dramatismo creciente hasta que acaba con los gritos desesperados de Unamuno: «No soy ni bolchevique, ni fascista. ¡Estoy solo! Solo, como Croce en Italia». Para Kazantzakis, Unamuno es un guerrero desesperado (un 'desperado), un Don Quijote contemporáneo (según los versos que cita de Machado), un luchador de los que sabe engendrar la tierra de Castilla.

$\mathrm{Y}$, finalmente, pasemos al último literato griego que vamos a ver en este estudio en relación con la ciudad de Salamanca. Se trata de KOSTAS TSIRÓPOULOS

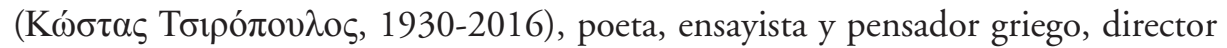

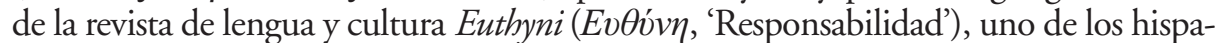
nistas griegos más relevantes, cuya obra no ha dejado de tender puentes entre la cultu-

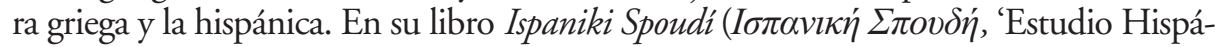
nico'), Tsirópoulos cuenta sus impresiones tras sus repetidos viajes a España. El libro

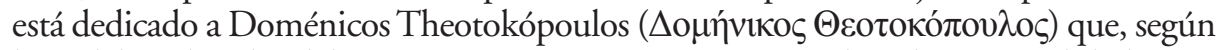
las palabras lúcidas del propio autor, representa un «maridaje de inmortalidad entre Grecia y España». En el prólogo de su estudio Tsirópoulos se declara un amante apasionado de España desde la primera vez que la visitó (España aparece, de hecho, como una figura femenina seductora que le provoca un flechazo, un 'coup de foudre'). El autor se da cuenta de que el amor por ella era algo que llevaba en la sangre:

Escondía dentro de mí el amor por España, había nacido para amarla pero tuvieron que suceder un cúmulo de acontecimientos para que me diera cuenta de eso. [...]

${ }^{5}$ Traducción de Styliani Voutsa. Todo el tomo que contiene el viaje de Kazantzakis a España está traducido al castellano por Joaquín Maestre (España y Viva la muerte, Júcar, Gijón, 1977) y Guadalupe Flores Liera (Viajando. España ;Viva la muerte!, Ediciones Clásicas, Madrid, 1998). 
Al final conocí España de cerca en 1961 y fue tal el amor que me fulminó que la seguí visitando durante cinco años consecutivos (Tsirópoulos, 1966: Prólogo).

Tsirópoulos, dentro del capítulo titulado -muy sugestivamente- "Castilla, pasión del cielo", habla con mucha perspicacia del paisaje de Castilla y de la espiritualidad que le despierta ${ }^{6}$. Dentro de «Castilla, pasión del cielo», Tsirópoulos dedica unas páginas a Salamanca, visitada tras su estancia en Alcalá de Henares. La ciudad está vista con ojo poético:

La recuerdo un atardecer del verano con su cielo lleno de cigüeñas que entraban y salían de los campanarios de sus iglesias. Es una ciudad con piedras antiguas que adquieren el color cálido del oro viejo cuando lo ilumina el brillo del sol. Todo sereno y elegante al lado de las aguas plateadas del Tormes (Tsirópoulos, 1966: 53).

La ciudad de Salamanca eleva a los que la visitan al espacio de lo sobrenatural, de lo metafísico. Igual que para Kazantzakis, para Tsirópoulos, la historia de la ciudad de Salamanca está profundamente ligada a dos grandes intelectuales, dos exponentes máximos de la literatura y del pensamiento español: Fray Luis de León y Miguel de Unamuno, ambos defensores acérrimos de la libertad y de los derechos humanos.

En aquel atardecer uno encuentra y saborea con sorpresa la trascendencia de la libertad. Es sintomático que, fieles al perfil moral de esta ciudad, de allí surgieron los símbolos de la libertad espiritual de España: Fray Luis de León y don Miguel de Unamuno. Ambos probaron el pan amargo del destierro y pasaron su vida luchando por defender los derechos espirituales del hombre (Tsirópoulos, 1966: 53).

El autor confiesa que por la noche se sentó un buen rato a los pies de la estatua de Fray Luis sintiendo cómo el silencio nocturno de alrededor se cargaba por la presencia del fraile.

Los días que siguieron Tsirópoulos visitó la capilla de la Universidad, la Casa de Unamuno, la Casa de las Conchas, la Casa de las Muertes y, cuando ya se sintió totalmente contagiado por la fiebre intelectual de la ciudad, bajó al final hasta el río, «allí donde la estatua desgastada del toro»:

${ }^{6}$ «Subiendo desde Cataluña y pasando por la antigua Zaragoza con su Virgen del Pilar [...] se descubre ante mis ojos el duro, seco mar de Castilla. ¡Qué paisaje más virtuoso es este, lleno de humildad y solidez interior! Por aquí desnudo como el pecho de un antiguo kuros, por allí ligeramente verde como axila masculina, emanando una sensación de hombría y concentración. En este lugar tu espíritu se modifica. [...] En Castilla entras no para disfrutar sino para sufrir. [...] El paisaje nos aprieta, nos invade, nos libera de lo terrenal, el paisaje de Castilla nos pone a prueba en un fuego secreto pero firme. Cae poco a poco la noche. Noche de Castilla inolvidable, noche que despierta la conciencia del abismo dentro de mí. Y de ese abismo sale un nuevo hombre que reclama sus derechos. El paisaje despierta «el encanto de la santidad o de la locura», Castilla enciende el anhelo del cielo, mientras que Cataluña nos llenaba de la angustia de esta vida». (Tsirópoulos, 1966: 36-37). 
Bajé para encontrarte a ti, Lazarillo de Tormes, gorrioncito que reías entre tus lágrimas y tu inocencia amarga. [...] A ti te creó el artesano desconocido cogiendo tierra de esta gran ciudad que está llena de revelaciones, de noches cargadas de electricidad de tempestades secretas, y convirtió la poesía y la sabiduría en asunto inmanente del corazón humano, honor y dignidad del hombre.

Aguas y árboles frondosos. Ahora la ciudad sube dorada como un cetro en las manos de Castilla (Tsirópoulos, 1966: 53).

Por nuestra parte, como licenciados de la Universidad de Salamanca y por ocho años colegiales del Colegio Universitario Fray Luis de León, compartimos plenamente la admiración y el entusiasmo de ambos intelectuales griegos, de Kazantzakis y de Tsirópoulos, ante una ciudad tan seductora como Salamanca. Recordemos las palabras de Cervantes, escritas en la pared de la Universidad que da a la Plaza de Anaya: "Salamanca que enhechiza la voluntad de volver a ella a todos los que de su apacibilidad de vivenda han gustado». En cuanto a los profesores D. Paramonaris y N. Rodinós, tenemos que reconocer que, como griegos, nos sentimos muy emocionados de visitar en esta Universidad -ya de más de ochocientos años de vida- las mismas aulas donde aquellos docentes paisanos enseñaron en el siglo XVII. Pero un griego de hoy se siente sobre todo orgulloso por el hecho de que la ciudad de Salamanca fue siempre la cuna, a nivel nacional e internacional, de los estudios humanísticos griegos, tema que podría alimentar -como señalamos al principio- un campo de investigación sorprendentemente amplio e interesante.

La conclusión a la que se llega tras este breve recorrido histórico de los cuatro intelectuales griegos que estuvieron en Salamanca es que los lazos entre la ciudad de Salamanca y el Helenismo no se perdieron a través de los siglos sino, al contrario, se forjaron de varias maneras: por el griego clásico que se enseñó siempre en esta Universidad, por los profesores griegos o chipriotas que enseñaron en ella, por los estudiosos y pensadores griegos que la visitaron, admiradores de su cultura y de su universalmente famosa Universidad. Y estamos convencidos -y así concluimos nuestro estudio- de que la tierra de Helmántica seguirá siendo una fuente de inspiración para todos los griegos que se sentirán atraídos por su histórica Universidad y por su larga tradición en estudios clásicos, en Studia Humanitatis.

RECIBIDO: octubre 2020; ACEPTADO: febrero 2021.

\section{BIBLIOGRAFÍA}

Dimadis, K. D. (1999): «Las crónicas periodísticas de Nikos Kazantzakis sobre la guerra civil española y su obra Viajando. España», en Olga Omatos (ed.), Tras las huellas de Kazantzakis, Athos-Pergamos, Granada, pp. 105-115.

FlORISTÁN IMÍzCOZ, A. (2007): «Catedráticos de griego en Salamanca y Alcalá: Diógenes Paramonaris (1617-1618) y Constantino Sofía (1629-1631). Notas prosopográficas», en A. BERnABÉ I. Rodríguez Alfageme (eds.), Фỉov okió. Studia philologiae in honorem Rosae Aguilar ab amicis et sodalibus dicata, Ed. Complutense, Madrid, pp. 241-252. 
GIL FERNÁNDEZ, L. (2010): «La enseñanza universitaria del griego y su valoración social», en F. L. LISI Bereterbide (ed.), Tradición clásica y universidad, Dykinson, Madrid, pp. 29-49.

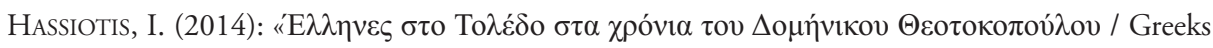
in Toledo during the Time of Domenicos Theotokopoulow», en N. HatzinikOlaOU (ed.).

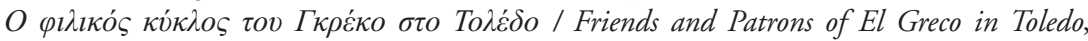
Athens, Benaki Museum, pp. 35-61.

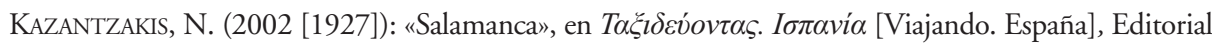
Kazantzakis, Atenas, pp. 41-43 [Traducción de Styliani VouTSA].

Legrand, É. (1903): Bibliographie Hellénique, tomo v, París, p. 234.

MurZAKU, I. A. (2009): «Neofito Rodinò, The Scholarly Monk and Missionary (1576 or 1577-1659)», en Returning Home to Rome: The Basilian Monks of Grottaferrata in Albania, Analekta Kryptoferris 7, Grottaferrata, pp. 72-75.

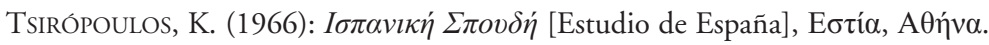

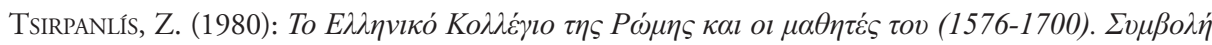

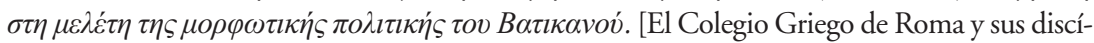

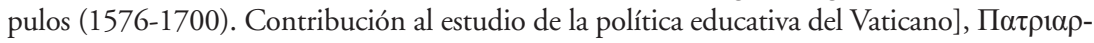

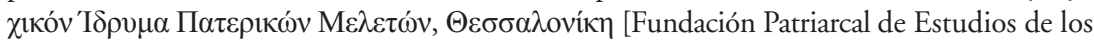
Santos Padres, Tesalónica].

VouTSA, S. (2007): «Nikos Kazantzakis y Miguel de Unamuno: dos gigantes del espíritu se encuentran en Salamanca», en A, ChaguaCeda Toledano (ed.), Miguel de Unamuno, estudios sobre su obra, vol. 4 [Cuadernos de la Cátedra Unamuno], Ediciones Universidad, Salamanca, pp. 127-131. 
